\title{
SÍNTESIS Y CARACTERIZACIÓN DE NANOESTRUCTURAS TIPO COBRE-SELENIO OBTENIDAS MEDIANTE LAS TÉCNICAS DE MICROONDAS Y MECANOSÍNTESIS
}

\author{
Aldo Javier Guzmán Duxtan ${ }^{*}$, Elvis Mauricio Jiménez Peña ${ }^{a}$
}

\begin{abstract}
RESUMEN
En este trabajo se describe la síntesis de nanoestructuras de seleniuro de cobre, utilizando la técnica de microondas y mecanosíntesis. En la síntesis asistida por microondas, el proceso se realizó en un horno microondas modificado, para ello, a una solución de sulfito de sodio se le añadió selenio en polvo, esta mezcla fue sometida a radiación microondas al $40 \%$ formando así el selenosulfato de sodio para luego agregarle acetato de cobre manteniendo la proporción $\mathrm{Cu}: \mathrm{Se}$ (1:1) mientras se sometía nuevamente a irradiación, obteniendo al finalizar un precipitado negro de seleniuro de cobre. La otra técnica es la mecanosíntesis, donde se molió polvos de cobre y selenio bajo atmósfera inerte, utilizando un molino SPEX 8000M, obteniendo seleniuro de cobre. Los productos fueron caracterizados mediante DR-X, FRXED, MEB, EDX, UV-Vis. Los resultados indican que se formaron las fases $\mathrm{Cu} 2 \mathrm{Se}, \mathrm{Cu} 3 \mathrm{Se} 2$ y Cu1.8Se. Empleando las ecuaciones de Scherrer y Williamson-Hall se determinó el diámetro promedio del cristalito entre 8 y $83 \mathrm{~nm}$, y con la ayuda del programa OriginPro 2017, se calcularon las microtensiones que estuvieron entre 0.00105 a $0.01031 \mathrm{~Pa}$. La banda de energía prohibida se obtuvo empleando el ploteo de Tauc, obteniendo valores entre 1 y $2 \mathrm{eV}$.
\end{abstract}

Palabras clave: Selenio, microondas, mecanosíntesis, seleniuro de cobre.

\section{SYNTHESIS AND CHARACTERIZATION OF COPPER-SELENIO TYPE NANOSTRUCTURES OBTAINED THROUGH MICROWAVE AND MECHANOSYNTHESIS TECHNIQUES}

\begin{abstract}
In this work, the synthesis of copper selenide nanostructures is described, using the microwave and mechanosynthesis technique. In microwave-assisted synthesis, the process was carried out in a modified microwave oven. To this a solution of sodium sulfite was added with selenium powder, this mixture was subjected to microwave radiation at $40 \%$, thus forming sodium selenosulphate for then add copper acetate maintaining the $\mathrm{Cu}$ : Se ratio

\footnotetext{
a Facultad de Química e Ing. Química, Universidad Nacional Mayor de San Marcos, Calle German Amezaga 375, Ciudad Universitaria, Lima, Perú.

*aldo.guzman@unmsm.edu.pe
} 
(1: 1) while undergoing irradiation again, obtaining at the end a black precipitate of copper selenide. The other technique is mecanosynthesis, where copper and selenium powders were ground under inert atmosphere, using a SPEX 8000M mill, obtaining copper selenide. The products were characterized by DR-X, FRX-ED, MEB, EDX, UV-Vis. The results indicate that the $\mathrm{Cu} 2 \mathrm{Se}, \mathrm{Cu} 3 \mathrm{Se} 2$ and $\mathrm{Cu} 1.8 \mathrm{Se}$ phases were formed. Using the equations of Scherrer and Williamson-Hall, the average diameter of the crystallite was determined between 8 and $83 \mathrm{~nm}$, and with the help of the OriginPro 2017 program, microtensions that were between 0.00105 to $0.01031 \mathrm{~Pa}$ were calculated. The banned energy band was obtained using the plot of Tauc, obtaining values between 1 and $2 \mathrm{eV}$.

Key words: microwave, mecanosynthesis, copper, selenium.

\section{INTRODUCCIÓN}

En los últimos años las nanoestructuras de seleniuro de cobre han tenido un alto interés dado que el seleniuro de cobre posee propiedades fascinantes y por ello amplias aplicaciones en campo tecnológico como: convertidores termoeléctricos ${ }^{1}$, filtros ópticos ${ }^{2}$, dispositivos fotoelectrónicos de alta eficiencia ${ }^{3}$, superconductores iónicos ${ }^{4}$, sensores de gases ${ }^{5}$, células solares $^{6} \mathrm{y}$ fotocatalizadores ${ }^{7}$ que permiten degradar productos químicos peligrosos. Es por eso que se vienen utilizando e implementando métodos para su síntesis como el solvotermal ${ }^{8}$, irradiación gamma ${ }^{9}$, sonoquímico ${ }^{10}$, electrodeposición ${ }^{11}$, evaporación al vacío ${ }^{12}$, coloidal ${ }^{13}$, deposición de baño químico ${ }^{14}$, deposición química de vapor $^{15} \mathrm{y}$ deposición por láser pulsado $^{16}$. El seleniuro de cobre es un semiconductor compuesto extrínseco tipo p, existe en diferentes composiciones estequiométricas ${ }^{17}\left(\mathrm{CuSe}, \mathrm{Cu}_{2} \mathrm{Se}, \mathrm{Cu}_{3} \mathrm{Se}_{2}, \mathrm{CuSe}_{2}, \mathrm{Cu}_{5} \mathrm{Se}_{4}\right)$ y no estequiométricas $^{18}\left(\mathrm{Cu}_{2-\mathrm{x}} \mathrm{Se}\right)$. Este material es potencialmente alternativo para sustituir al silicio en dispositivos electrónicos y particularmente en células solares por poseer una banda de energía prohibida entre 1 y $2.3 \mathrm{eV}^{19}$. En nuestros laboratorios empleamos dos métodos asequibles para la obtención de las nanoestructuras tipo cobre-selenio, por microondas que representa una técnica alternativa que proporciona la energía térmica a un proceso fisicoquímico ventajas comparativas como el ahorro de tiempo, energía, rapidez y eficiencia que serían difíciles de conseguir por otros métodos convencionales ${ }^{20}$. Además, esta es una técnica amigable con el medio ambiente y una alternativa que apoya el desarrollo de nuevas líneas de investigación. Por otra parte, tenemos la mecanosíntesis ${ }^{21}$ o molienda mecánica, que es considerada una técnica moderna, útil y versátil, ha permitido producir materiales en fases fuera del equilibrio termodinámico ( $\sin$ la necesidad de recurrir a solventes químicos nocivos que perjudican el medio ambiente), tales como: aleaciones, soluciones sólidas extendidas y/o amorfas, fases nanovítreas y cuasicristales. Las nanoestructuras preparadas de seleniuro de cobre, luego, se caracterizaron por determinación de sus fases estructurales, composición química y morfología. Además, sus propiedades ópticas se analizaron mediante espectroscopia UV-Vis y para determinar la banda de energía prohibida se utilizó el ploteo de Tauc ${ }^{22}$. 


\section{PARTE EXPERIMENTAL}

\section{Síntesis de nanoestructuras tipo Cu-Se por vía microondas}

Para este experimento, se utilizó la proporción de masas $\mathrm{Cu}: \mathrm{Se}=1: 1$ (CuSe (A)). Primero, en un vaso de precipitado, se preparó selenosulfato de sodio $\left(\mathrm{Na}_{2} \mathrm{SeSO}_{3}\right)$, disolviendo 0.263 $\mathrm{g}$ de selenio $(0.0033 \mathrm{~mol})$ en polvo con $50 \mathrm{~mL}$ de una solución de sulfito de sodio $1,1 \mathrm{M}$. La mezcla resultante de color negro con un $\mathrm{pH} \approx 9$ se homogenizó durante 10 minutos y se vertió en un balón de $250 \mathrm{~mL}$. Seguidamente, se colocó el balón en el horno de microondas (figura1) y se irradió con una potencia de $40 \%$ durante dos intervalos de 15 minutos con reflujo y agitación. Al transcurrir el tiempo se observó que la solución se tornó transparente, por otro lado, se disolvió $0.751 \mathrm{~g}$ de acetato de cobre $(0.0041 \mathrm{~mol}$ de cobre $)$ en $50 \mathrm{~mL}$ de agua destilada. Nuevamente, se continuó la irradiación microondas a la solución transparente bajo las mismas condiciones (potencia: $40 \%$, por 15 minutos) y en ese intervalo de tiempo de le adicionó la solución de acetato de cobre de manera continua mediante un embudo Schlenk, continuando con la irradiación por otros 15 minutos, se logró ver la formación de un precipitado de color negro en el interior del balón.

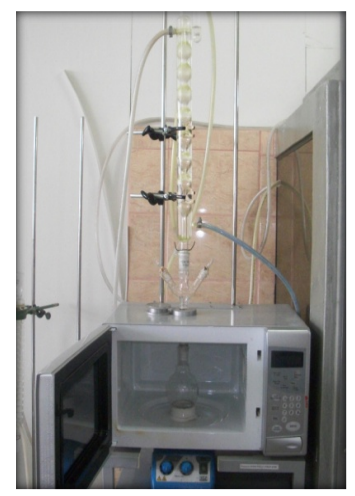

Figura 1. Microondas modificado.

Por último, el precipitado, se filtró en un matraz erlenmeyer utilizando papel filtro y lavándolo con agua destilada caliente y etanol absoluto, para luego llevar a la estufa para secado por 2 horas a una temperatura de $80^{\circ} \mathrm{C}$ durante 20 minutos. A esta única muestra se le hizo posteriormente tratamiento térmico colocando solo el producto sin el papel filtro en un crisol que se llevó a una mufla y se calentó aproximadamente 2 horas a $800^{\circ} \mathrm{C}$. Controlar la formación de las fases de seleniuro de cobre es complicado porque tienden a formarse varias durante el proceso de síntesis por eso se realizaron otras dos experiencias con proporciones numéricas sencillas para analizarlas y quedarse con aquella donde se obtenga la fase pura. Las otras dos muestras sintetizadas empleando esta técnica fueron las $\mathrm{Cu}: \mathrm{Se}=2: 1$ y $\mathrm{Cu}: \mathrm{Se}=3: 2$, denominadas $\mathrm{CuSe}(\mathrm{B})$ y $\mathrm{CuSe}(\mathrm{C})$, respectivamente, manteniendo fija la potencia de irradiación y el tiempo, pero variando la cantidad de agente reductor. 


\section{Síntesis de nanoestructuras tipo Cu-Se por mecanosíntesis}

La síntesis comienza con el cálculo de las masas de cada elemento que forma parte del sistema $\mathrm{Cu}-\mathrm{Se}$, manteniendo la estequiometría $\mathrm{Cu}: \mathrm{Se}=2: 1$. Para la nanoestructura $\mathrm{Cu}_{2} \mathrm{Se}$ se tiene:

$$
\begin{aligned}
m_{S e} & =(38.32 \%) * \text { masa }_{\text {total }} \\
& m_{C u}=(61.68 \%) * \text { masa }_{\text {total }}
\end{aligned}
$$

La masa total se calcula mediante la siguiente ecuación:

$$
\frac{\text { villas }}{\text { Carga }}=\frac{\text { masa }_{\text {totaldebolas }}}{\text { masa }_{\text {total }}}
$$

En este trabajo la relación villas/carga23 empleada fue de 10:1, el peso de cuatro villas de acero fue de 33.1474 gramos, luego reemplazando en la ecuación 3:

$$
\begin{aligned}
\frac{10}{1} & =\frac{33.1474}{\text { masa }_{\text {total }}} \\
\text { masa }_{\text {total }} & =3.3147 \mathrm{~g}
\end{aligned}
$$

Reemplazando este valor en las ecuaciones 1 y 2 se obtiene:

$$
\begin{aligned}
& m_{S e}=(38.32 \%) * 3.3147=1.2702 g \\
& m_{C u}=(61.68 \%) * 3.3147=2.0445 g
\end{aligned}
$$

Teniendo todas las masas pesadas, se procedió a trabajar en una cámara de vacío $(0,05$ bar) saturada de gas argón; en estas condiciones, se adicionan los polvos y las villas en un contenedor cilíndrico de base plana para posterior sellado, este contenedor es propio del Molino Vibratorio (SPEX, 8000M) que se observa en la figura 2. El contenedor se instaló en el brazo mecánico del molino y se trabajó en intervalos de molienda de 30 minutos con 10 minutos de pausa entre cada molienda. Para un tiempo neto de molienda de 12 horas se tomaron pequeñas muestras bajo condiciones de atmósfera inerte en la cámara ya mencionada, los intervalos de tiempo fueron de 0 (blanco), 1, 3, 6 y 12 horas para evaluar el desarrollo de dicha molienda. No se prepararon y molieron muestras con la relación $\mathrm{Cu}: \mathrm{Se}=1: 1 \mathrm{y} \mathrm{Cu}: \mathrm{Se}$ $=3: 2$, debido a la indisponibilidad del equipo de molienda que era empleado en muchos trabajos de investigación en la facultad de física. 


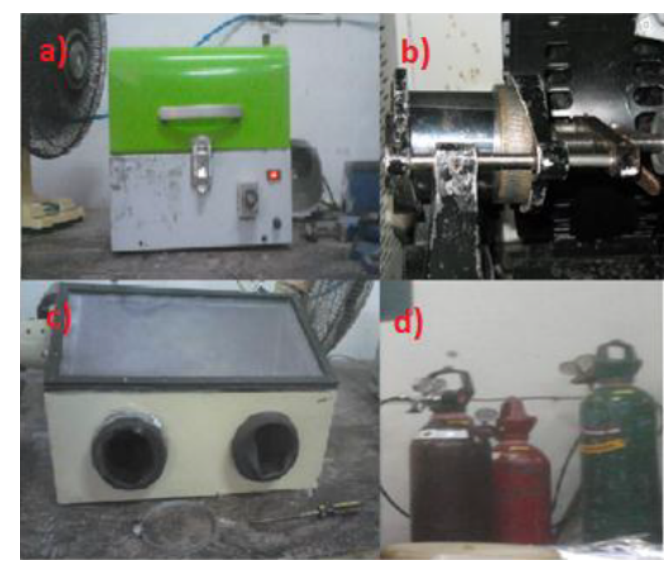

Figura 2. a) Molino de sistema vibratorio modelo SPEX 8000M; b) Motor y brazo mecánico; c) cámara de guantes; d) Cilindros para gases inertes.

\section{RESULTADOS Y DISCUSIÓN}

\section{Caracterización estructural, estudio de fases y determinación de tamaño de partícula} Los siguientes difractogramas resultan de la formación de muestras mediante la técnica microondas. En la figura 3 se observa el difractograma de la muestra $\mathrm{CuSe}(\mathrm{A})$ y las distintas fases del seleniuro de cobre formado cuando se mantuvo la relación $\mathrm{Cu}: \mathrm{Se}=1: 1$, la primera corresponde a la fase $\mathrm{Cu}_{3} \mathrm{Se}_{2}(P \overline{4} 21 \mathrm{~m})$ tetragonal tipo umangita $(239$-ICSD) que presenta picos de difracción con mayor intensidad en ángulos $2 \Theta=25.05,27.87,28.74,39.65,49.89$ y $51,52^{\circ}$ que tienen por planos cristalinos (101), (200), (111), (220), (311), (202). La segunda fase $\mathrm{Cu} 2 \mathrm{Se}(\mathrm{F} 3 \mathrm{~mm})$ cúbica tipo berzelianita (33628-ICSD) muestra picos con alta intensidad en $2 \Theta=26.96$ y $44.79^{\circ}$ con planos correspondientes a (111) y (220).

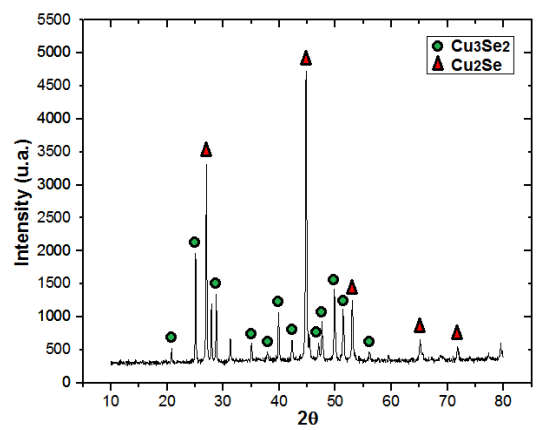

Figura 3. Difractograma de Rayos X de la muestra CuSe(A). 
El difractograma de la figura 4 pertenece al espectro de la muestra CuSe (B) y presenta la mezcla de dos fases, en la cual, a diferencia de la primera muestra sintetizada se realizó un cambio en la relación cobre/selenio a $\mathrm{Cu}: \mathrm{Se}=2: 1$. La fase $\mathrm{Cu}_{1.8} \mathrm{Se}(\mathrm{F} 4 \overline{3} \mathrm{~m})$ cúbica tipo berzelianita (77376-ICSD) posee picos de difracción característicos en los ángulos $2 \Theta=26.93$, 44.74 y $52.24^{\circ}$ dados por los planos cristalinos (111), (220) y (331). El difractograma revela

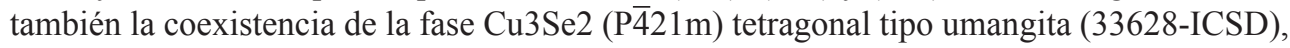
donde se puede observar que los picos de esta fase presentan menores intensidades en comparación a lo mostrado en la figura 3.

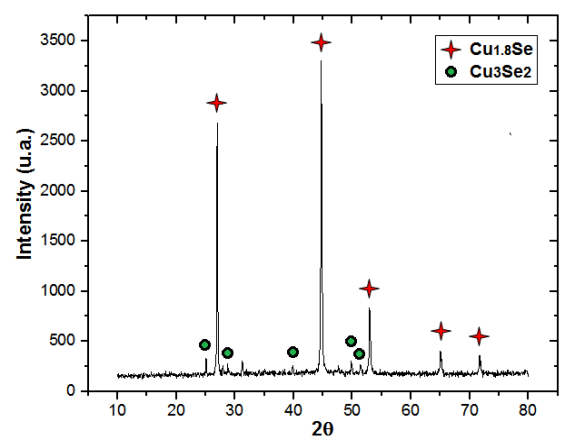

Figura 4. Difractograma de rayos $\mathrm{X}$ de la muestra CuSe (B).

En la figura 5, se observa el difractograma de la muestra CuSe (C), en la cual se volvió a cambiar la relación a $\mathrm{Cu}: \mathrm{Se}=3: 2$. Este difractograma indica la presencia de una sola fase pura, identificada como $\mathrm{Cu}_{1.8} \mathrm{Se}(\mathrm{F} 4 \overline{\mathrm{3m}})$ cúbica tipo berzelianita (77376-ICSD), la cual presenta picos con intensidades fuertes que aparecen en los ángulos $2 \Theta=26.93,44.63$ y $52.88^{\circ}$ correspondientes a los planos cristalinos (111), (200) y (220). Además, no aparece la fase $\mathrm{Cu}_{3} \mathrm{Se}_{2}$ que se presentaba en los anteriores difractogramas, por lo tanto, la nanoestructura $\mathrm{Cu}_{1.8} \mathrm{Se}$ posee una mayor pureza.

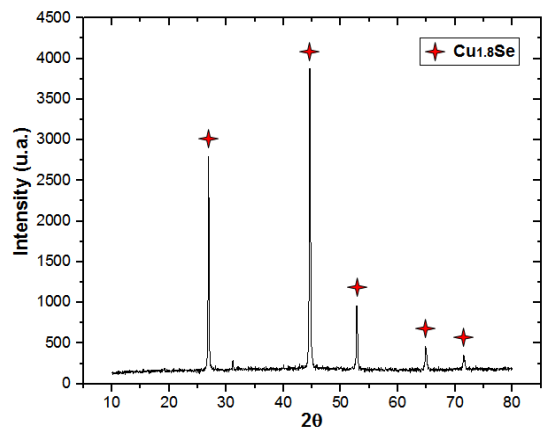

Figura 5. Difractograma de Rayos $X$ de la muestra CuSe (C). 
Es conocido que los seleniuros de cobre poseen diferentes estados polimórficos ${ }^{11}$ al incrementar la temperatura, es por ello que se realizó tratamiento térmico a la primera muestra sintetizada CuSe (A) cuyo difractograma se aprecia en la figura 3, la cual presenta las fases $\mathrm{Cu}_{3} \mathrm{Se}_{2} \mathrm{y} \mathrm{Cu}_{2} \mathrm{Se}$. El resultado del calentamiento se observa en el difractograma de la figura 6, donde ambas fases desaparecieron dejando solo la señal del óxido de cobre $(\mathrm{CuO})$, es muy probable que la fase $\mathrm{Cu}_{2} \mathrm{Se}$ haya sufrido la transformación polimórfica a $150{ }^{\circ} \mathrm{C}$ y que haya ocurrido la ruptura del $\mathrm{Cu}_{3} \mathrm{Se}_{2}$ en $\mathrm{Cu}_{2-\mathrm{x}} \mathrm{Se}$ y CuSe. Sin embargo, al calentar se sobrepasa el punto de ebullición del selenio $\left(684,8^{\circ} \mathrm{C}\right)$ produciendo el desprendimiento rápido del selenio gaseoso quedando en la muestra el cobre que reacciona con el oxígeno produciendo $\mathrm{CuO} . \mathrm{Al}$ observar este resultado no se hizo el mismo tratamiento con las demás muestras de seleniuro de cobre porque nuevamente se daría el desprendimiento de todo el selenio en forma de gas quedándose solo el óxido de cobre.
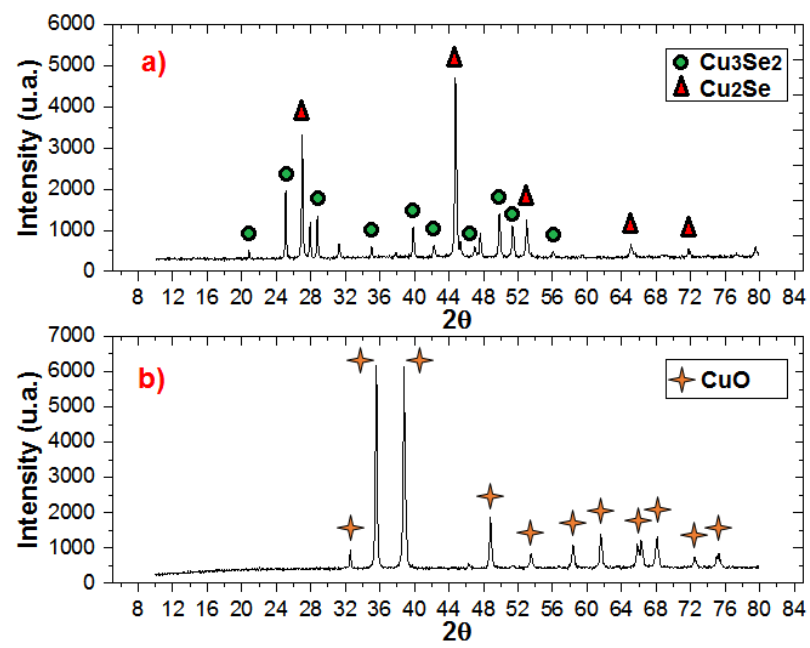

Figura 6. a) Difractograma de rayos $\mathrm{X}$ de la muestra $\mathrm{CuSe}(\mathrm{A})$ antes del tratamiento térmico; b) Difractograma de rayos $\mathrm{X}$ después de 2 horas a $800^{\circ} \mathrm{C}$.

Es evidente a partir de los difractogramas de rayos X anteriores la importancia de la proporción $\mathrm{Cu} / \mathrm{Se}$ usada en cada experimento para la formación de las distintas fases de seleniuro de cobre. Esto ocurre en el medio de reacción que contiene iones de cobre y selenio con diferentes potenciales de reducción, el ion selenio tiene un mayor potencial de reducción por lo tanto este agente reductor pierde sus electrones volviéndose $\mathrm{Se}^{0}$ estas partículas iniciales se forman y comienzan a crecer, a su vez los iones cobre ganan los electrones y se vuelven $\mathrm{Cu}^{0}$ los cuales quedan atrapados e incluidos en los espacios tetraédricos u octaédricos de la red cristalina del selenio formándose así las diferentes fases de la nanoestructura. Para explicar mejor la formación de las dos fases presentes en el difractograma (figura 3) de la muestra CuSe (A), se parte del siguiente mecanismo de reacción: 
La reacción al agregar un exceso de sulfito de sodio (agente reductor) y selenio, tal como se indica cuando se emplea la técnica por microondas, da paso a un medio básico donde ocurre la hidrolisis del sulfito de sodio y la formación del selenosulfato $\left(\mathrm{Na}_{2} \mathrm{SeSO}_{3}\right)$, reacciones 5 y 6:

$$
\begin{array}{r}
2 \mathrm{SO}_{3}^{2-}+2 \mathrm{H}_{2} \mathrm{O}+2 \mathrm{e}^{-} \rightleftarrows \mathrm{S}_{2} \mathrm{O}_{4}^{2-}+4 \mathrm{OH}^{1-} \\
\mathrm{NaSO}_{3}+\mathrm{Se} \rightarrow \mathrm{Na}_{2} \mathrm{SeSO}_{3}
\end{array}
$$

El selenosulfato de sodio es la fuente de iones $\mathrm{Se}^{2-}$, este compuesto es inestable en medio básico y se disocia como ocurre en la siguiente reacción:

$$
\mathrm{Na}_{2} \mathrm{SeSO}_{3}+2 \mathrm{OH}^{1-} \rightleftarrows \mathrm{Na}_{2} \mathrm{SO}_{4}+\mathrm{Se}^{2-}+\mathrm{H}_{2} \mathrm{O}
$$

Al agregar acetato de cobre al medio de reacción parte de los iones cobre $\mathrm{Cu}^{2+}$ son reducidos hasta $\mathrm{Cu}^{1+}$ por el agente reductor sulfito como se da en la reacción 8 , para luego reaccionar con los iones seleniuro originados en la reacción 7 que conducen a la formación del $\mathrm{Cu}_{2} \mathrm{Se}$, que se muestra en la reacción 9:

$$
\begin{gathered}
\mathrm{Cu}^{2+}+1 \mathrm{e}^{-} \rightarrow \mathrm{Cu}^{1+} \\
2 \mathrm{Cu}^{1+}+\mathrm{Se}^{2-} \rightarrow \mathrm{Cu}_{2} \mathrm{Se}
\end{gathered}
$$

En la solución también ocurre que los iones $\mathrm{Cu}^{2+}$ y $\mathrm{Cu}^{1+}$ reaccionan con los iones seleniuro para producir la fase $\mathrm{Cu}_{3} \mathrm{Se}_{2}$ como se indica en:

$$
\mathrm{Cu}^{2+}+2 \mathrm{Cu}^{1+}+2 \mathrm{Se}^{2-} \rightarrow \mathrm{Cu}_{3} \mathrm{Se}_{2}
$$

Ambas fases formadas en la muestra $\mathrm{CuSe}(\mathrm{A})$ tienen porcentajes en pesos similares como se indica en la tabla 2, por lo tanto se puede afirmar que hay una proporción similar de iones $\mathrm{Cu}^{2+}$ y Cu$^{1+}$ durante la síntesis. En el difractograma de la muestra $\mathrm{CuSe}(\mathrm{B})$ mostrado en la figura 4, se aprecia que las intensidades de los picos característicos de la fase $\mathrm{Cu}_{3} \mathrm{Se}_{2}$ disminuyen drásticamente y se pierde la estequiometria $\mathrm{Cu}_{2} \mathrm{Se}$ dando lugar a la fase no estequiométrica $\mathrm{Cu}_{1.8} \mathrm{Se}$ que presenta una mayor intensidad. La formación de la fase no estequiométrica ocurre al cambiar las condiciones iniciales que permitían la existencia de la fase $\mathrm{Cu}_{2} \mathrm{Se}$ en la muestra $\mathrm{CuSe}(\mathrm{A})$, como reducir a la mitad el número de moles de selenio y sulfito de sodio utilizados durante el experimento con la muestra CuSe (B) donde se empleó la relación $\mathrm{Cu}: \mathrm{Se}=2: 1$ (tabla 1 ). La consecuencia directa es disminuir la concentración del selenosulfato de sodio formado tal como se indica en la reacción 6, además ocurre una variación del $\mathrm{pH}$ haciendo al medio menos básico en comparación al anterior experimento, ambos efectos producen un desplazamiento a la izquierda en la reacción 7 disminuyendo así la concentración de iones seleniuro provocando que la reacción 10 esté desfavorecida ya que esa reacción necesita más iones seleniuros ocasionando así la disminución de la fase $\mathrm{Cu}_{3} \mathrm{Se}_{2}$. A diferencia de los experimentos anteriores en la muestra CuSe (C) desapareció por completo la fase $\mathrm{Cu}_{3} \mathrm{Se}_{2}$ formándose solo la fase pura $\mathrm{Cu} 1.8 \mathrm{Se}$ en el difractograma de rayos $\mathrm{X}$ de la figura 5, esto ocurre porque se redujo la cantidad de moles de cobre utilizadas (tabla 1) al 
emplear la relación $\mathrm{Cu}: \mathrm{Se}=3: 2$, facilitando la acción del exceso de sulfito en reducir todos los iones $\mathrm{Cu}^{2+}$ a $\mathrm{Cu}^{1+}$ y desfavoreciendo por completo la reacción 10. Los porcentajes en pesos de la tabla 2, una vez más corroboran lo anterior puesto que el porcentaje en peso de la fase $\mathrm{Cu}_{3} \mathrm{Se}_{2}$ disminuye hasta el $17 \%$ en la muestra $\mathrm{CuSe}(\mathrm{B})$, mientras que en la muestra $\mathrm{CuSe}(\mathrm{C})$ desaparece dejando solo la fase $\mathrm{Cu}_{1.8}$ Se al $100 \%$.

Tabla 1. Cantidad de reactivos utilizados al inicio de la síntesis.

\begin{tabular}{ccccc}
\hline Muestra & Relación & $\begin{array}{c}\text { cobre } \\
(\mathbf{m o l})\end{array}$ & $\begin{array}{c}\text { selenio } \\
(\mathbf{m o l})\end{array}$ & $\begin{array}{c}\text { Sulfito de } \\
\text { sodio (mol) }\end{array}$ \\
\hline $\mathrm{CuSe}(\mathrm{A})$ & $1: 1$ & 0.0041 & 0.0033 & 0.0550 \\
$\mathrm{CuSe}(\mathrm{B})$ & $2: 1$ & 0.0041 & 0.0016 & 0.0275 \\
$\mathrm{CuSe}(\mathrm{C})$ & $3: 2$ & 0.0031 & 0.0016 & 0.0275 \\
\hline
\end{tabular}

Por otra parte, todos los procesos de molienda comprenden tres principales etapas que se dieron bajo atmósfera inerte para evitar que ingrese el oxígeno y se formen óxidos, los cuales son fases impuras no deseadas que aparecen frecuentemente durante la mecanosíntesis. En la etapa inicial, los polvos elementales de cobre y selenio son aplanados y forman estructuras laminares, las superficies creadas recientemente durante la fractura permiten que las partículas se junten y suelden en condiciones frías. En la etapa intermedia de la molienda los seguidos impactos de las bolas contra los polvos elementales incrementa el número de defectos, deslocalizaciones, vacantes, límites de granos. La presencia de estos defectos estructurales permite la difusión ultrarrápida, así como también la formación del seleniuro de cobre. Finalmente, en la última etapa, la composición final del $\mathrm{Cu}_{2} \mathrm{Se}$ formado se aproxima a la proporción de polvos elementales de $\mathrm{Cu}$ y Se usadas al inicio la cual se mantuvo en la relación $\mathrm{Cu}: \mathrm{Se}=2: 1$. La serie de difractogramas en la figura 7 pertenecen a la mezcla de polvos elementales que fueron molidos y posteriormente monitoreados durante diferentes intervalos de tiempo (horas) en el proceso de mecanosíntesis. A las $0 \mathrm{~h}$ corresponde a la mezcla de partida, por lo tanto solo aparecen las intensidades propias del cobre con estructura cúbica centrada en la cara y selenio con estructura hexagonal. 


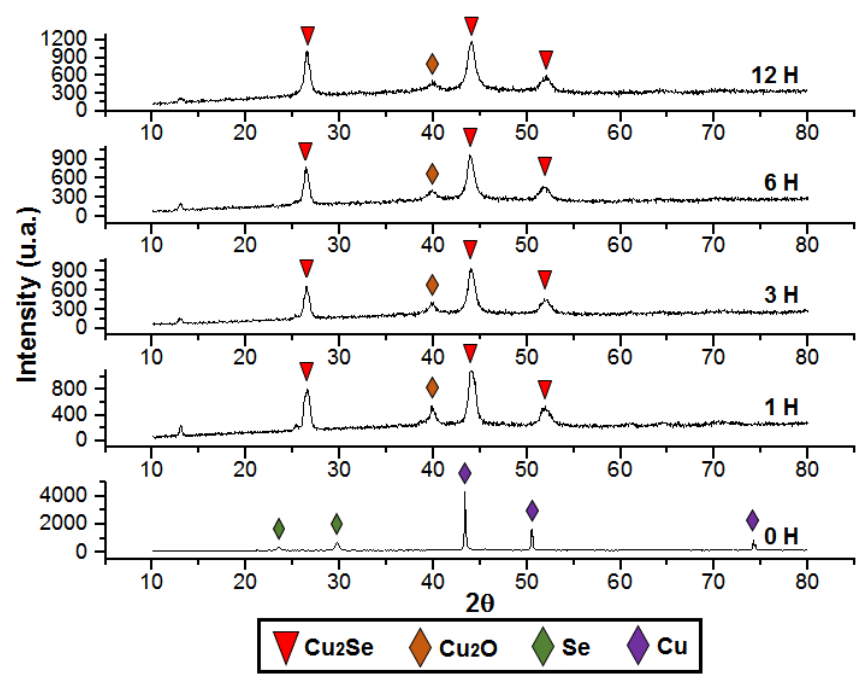

Figura 7. Difractogramas de Rayos X de las nanoestructuras de seleniuro de cobre obtenidas por mecanosíntesis.

Después de $1 \mathrm{~h}$ de molienda se puede observar la desaparición de las intensidades de los picos iniciales que evidencian la desaparición de los planos cristalográficos del $\mathrm{Cu}$ y $\mathrm{Se}$ para dar lugar a la formación de una nueva fase correspondiente a $\mathrm{Cu} 2 \mathrm{Se}(F 23)$ cúbica tipo berzelianita (JCPDS card 76-0136 ) que se formó por el continuo impacto de las bolas contra los polvos elementales iniciales, también se produjo óxido de cobre $\left(\mathrm{Cu}_{2} \mathrm{O}\right)$ probablemente al entrar la muestra en contacto con el aire cuando se realizaron las mediciones en el equipo de DR-X. Durante los siguientes intervalos de tiempo predominó la existencia de la fase $\mathrm{Cu} 2 \mathrm{Se}$, se observó que en los espectros analizados cada vez se iban incrementaron las intensidades que se relaciona con el grado de cristalinidad y el ancho de pico relacionado con la reducción de tamaño de partícula, los picos característicos se localizaron los ángulos $2 \Theta=26.54,44.03,52.15^{\circ}$ que tienen como coordenadas a los planos cristalinos (111), (220) y (311), respectivamente.

A partir de los difractogramas de rayos $X$ se realizaron refinamientos por el método Rietveld $^{14,15}$, con la finalidad principal de calcular el porcentaje de todas las fases de seleniuro de cobre presente en cada difractograma mostrado anteriormente. En concreto, se identificaron primero las fases presentes en cada difractograma utilizando el software Crystallographica Search-Match 2.1, luego se buscó la data (archivo) de estas fases en una base de datos cristalográficos y junto a los datos experimentales obtenidos, son estudiados en el software especializado MAUD v2.33 para refinar los difractogramas de las figuras 3, 4, 5 y 7 , con el fin de obtener el porcentaje de fases, parámetros de red entre otros. Las figuras 8,9 y 10 pertenecen a los refinamientos realizados en los difractogramas de las muestras sintetizadas mediante la técnica microondas, mientras que, la figura 11 es el difractograma 
refinado de la muestra molida por 12 horas durante la mecanosíntesis. Adicionalmente, los principales parámetros obtenidos aplicando el refinamiento Rietveld son mostrados en la tabla 2.

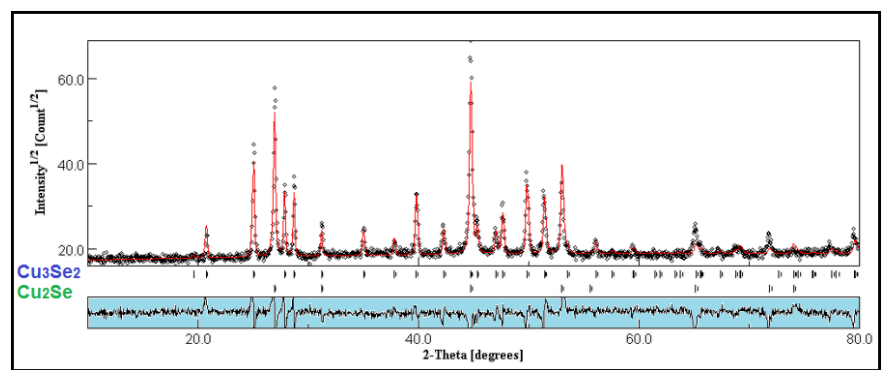

Figura 8. Difractograma de Rayos X con refinamiento de la muestra CuSe (A).

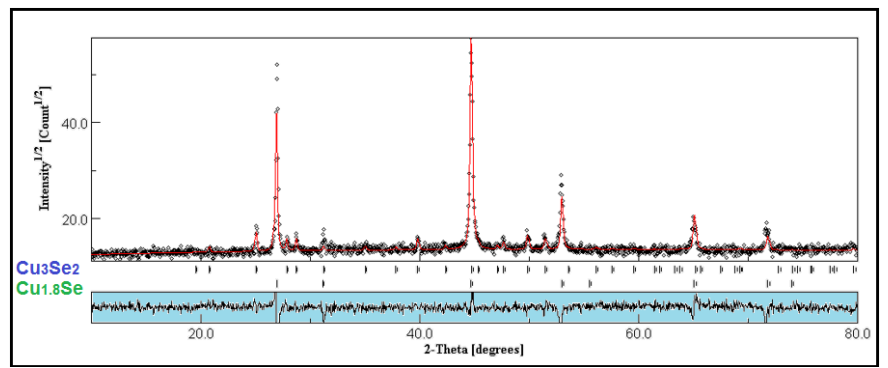

Figura 9. Difractograma de Rayos X con refinamiento de la muestra $\mathrm{CuSe}(\mathrm{B})$.

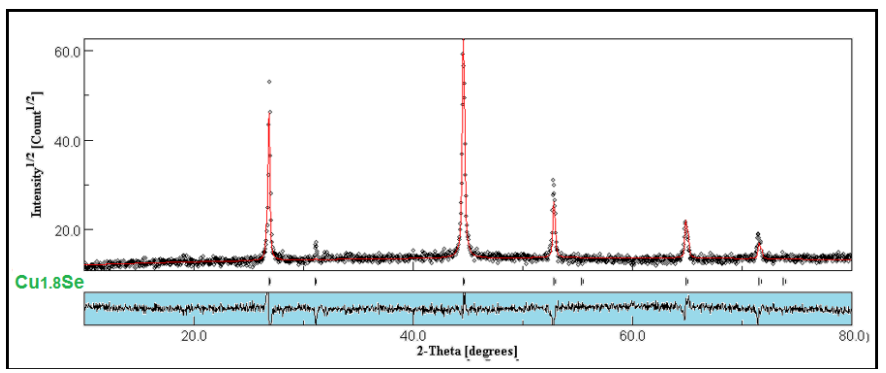

Figura 10. Difractograma de Rayos X con refinamiento de la muestra CuSe (C). 


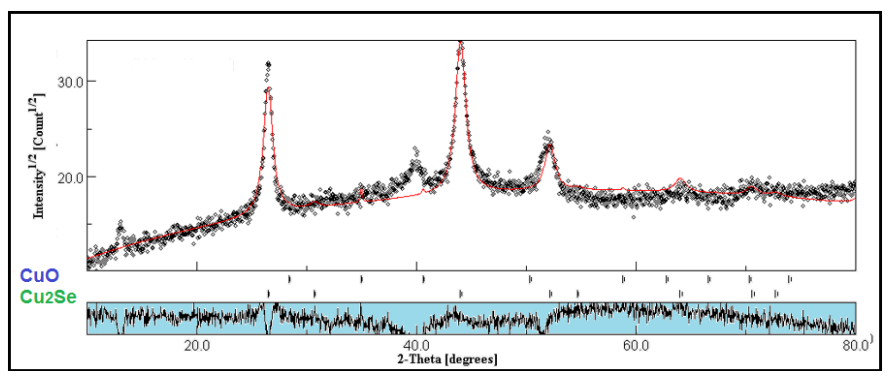

Figura 11. Difractograma de Rayos X y refinamiento de la fase Cu2Se obtenida por mecanosíntesis a las 12 horas.

Tabla 2. Parámetros obtenidos en el refinamiento de Rietveld de las muestras sintetizadas por las técnicas microondas y mecanosíntesis.

\begin{tabular}{ccccc}
\hline Muestra & Fase & $\begin{array}{c}\text { Parámetros de } \\
\text { red }(\AA)\end{array}$ & $\begin{array}{c}\text { Volumen de } \\
\text { celda }\left(\AA^{\mathbf{3}}\right)\end{array}$ & $\begin{array}{c}\text { \% Fases } \\
\text { CuSe }(\mathrm{A})\end{array}$ \\
& $\mathrm{Cu}_{2} \mathrm{Se}$ & $\mathrm{a}=\mathrm{b}=\mathrm{c}=5.720$ & 187.149 & 52.996 \\
& $\mathrm{Cu}_{3} \mathrm{Se}_{2}$ & $\mathrm{a}=\mathrm{b}=6.394 \mathrm{c}=4.267$ & 174.449 & 47.004 \\
\hline \multirow{2}{*}{$\mathrm{CuSe}(\mathrm{B})$} & $\mathrm{Cu}_{3} \mathrm{Se}_{2}$ & $\mathrm{a}=\mathrm{b}=6.395 \mathrm{c}=4.261$ & 174.258 & 17.062 \\
& $\mathrm{Cu}_{1.8} \mathrm{Se}$ & $\mathrm{a}=\mathrm{b}=\mathrm{c}=5.7261$ & 187.739 & 82.938 \\
\hline $\mathrm{CuSe}(\mathrm{C})$ & $\mathrm{Cu}_{1.8} \mathrm{Se}$ & $\mathrm{a}=\mathrm{b}=\mathrm{c}=5.740$ & 189.119 & 100 \\
\hline \multirow{2}{*}{$\mathrm{Cu}_{2} \mathrm{Se}$} & $\mathrm{Cu}_{2} \mathrm{Se}$ & $\mathrm{a}=\mathrm{b}=\mathrm{c}=5.812$ & 196.32 & 80.323 \\
& $\mathrm{Cu}_{2} \mathrm{O}$ & $\mathrm{a}=\mathrm{b}=\mathrm{c}=4.482$ & 90.034 & 10.667 \\
\hline
\end{tabular}

El diámetro promedio del cristalito (D) y la tensión de la nanoestructura $(\varepsilon)$ de las nanoestructuras se calcularon mediante las ecuaciones de Williamson-Hall ${ }^{17}$ y Scherrer ${ }^{18}$. El procedimiento del cálculo parte con los difractogramas ya refinados de las muestras sintetizadas, la data de estos difractogramas se exporta mediante el software MAUD, hacia el programa OriginPro 2017 b9.4.0.220 en donde se separaron las fases que podrían estar presentes en el difractograma. Al tratar este difractograma refinado (figura 3) de la muestra CuSe (A) se logra separar las fases tal como se muestra en la figura 12 .
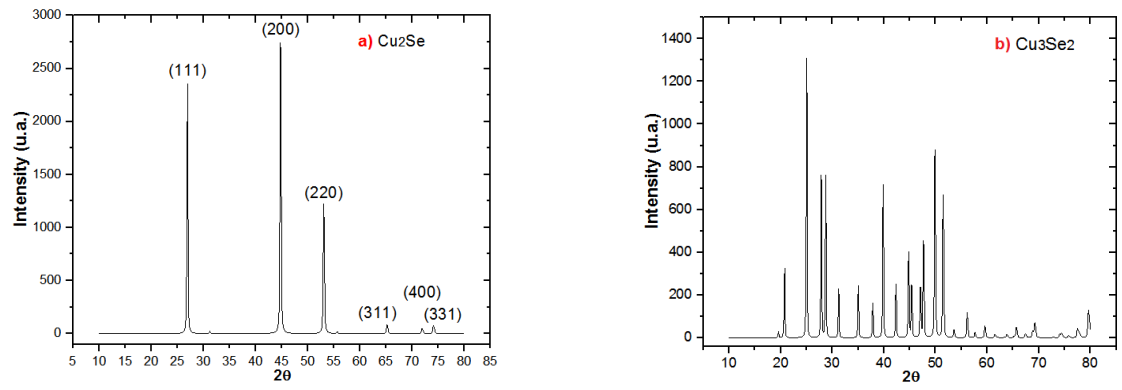

Figura 12. Difractogramas de Rayos $X$ separados de la fase Cu2Se(a) y de la fase $\mathrm{Cu}_{3} \mathrm{Se}_{2}$ en (b). 
A partir del difractograma figura 12 (a) se ajusta el pico (111) para un análisis deconvolutivo al perfil de la función de ajuste PsdVoigt1 para obtener los parámetros $\mathrm{X}_{\mathrm{c}} \mathrm{y} \mathrm{W}$, tal como se muestran en la figura 13 .

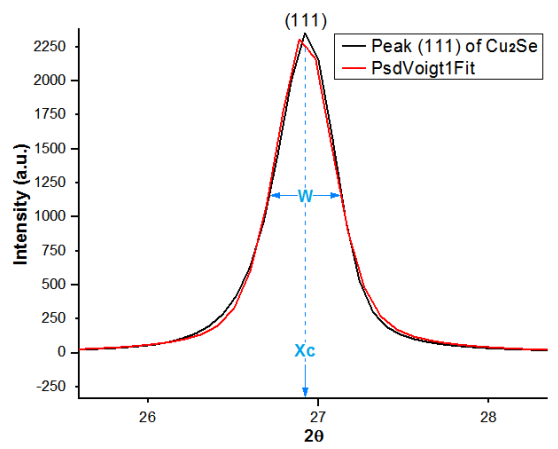

Figura 13. Ajustes de picos de la fase Cu2Se perteneciente al plano (111).

Luego se registran los valores paramétricos del pico en la tabla 3, siendo W (también denominado $\beta$ o FWHM) la anchura del pico a altura media del mismo y Xc el ángulo de difracción $2 \Theta$.

Tabla 3. Datos del pico (111) de la fase $\mathrm{Cu}_{2} \mathrm{Se}$.

\begin{tabular}{lccc}
\hline Función & \multicolumn{3}{c}{ PsdVoigt1 } \\
\hline Plano & Parámetro & Valor & $\begin{array}{c}\text { Error } \\
\text { estándar }\end{array}$ \\
$(111)$ & $\mathrm{Y}_{0}$ & -3.0955 & 2.41503 \\
& $\mathrm{X}_{\mathrm{c}}$ & 26.95876 & 0.001 \\
& $\mathrm{~A}$ & 658.312 & 7.16997 \\
& $\mathrm{~W}\left(^{\circ}\right)$ & 0.20925 & 0.00236 \\
& $\mathrm{mu}$ & 0.63513 & 0.02827 \\
\hline $\mathrm{Chi}^{2}$ & \multicolumn{3}{c}{462.472446} \\
\hline $\mathrm{R}^{2}$ & \multicolumn{3}{c}{0.99725} \\
\hline
\end{tabular}

Convirtiendo y reemplazando los valores de Xc $\left(13.47938^{\circ}\right)$ y W $\left(0.20925^{\circ}=0.00365211 \mathrm{rad}\right)$ en la ecuación de Williamson-Hall:

$$
\begin{gathered}
\beta_{h k l} \cos \theta=\frac{k \lambda}{D}+4 \varepsilon \operatorname{sen} \theta \\
(0.00365211) \cdot \cos (13.47938)=\frac{(0.9)(0.1546)}{D}+(4) \cdot(\varepsilon) \cdot \operatorname{sen}(13.47938)
\end{gathered}
$$


El mismo procedimiento se aplica a los demás picos de la figura 12 (a), dando otras cinco ecuaciones análogas a la anterior y correspondientes a los planos (200), (220), (311), (400) y (331). Las ecuaciones se utilizaron para plotear el gráfico de la figura 14, luego se ajustó los puntos a una ecuación lineal para obtener los valores del intercepto y pendiente.

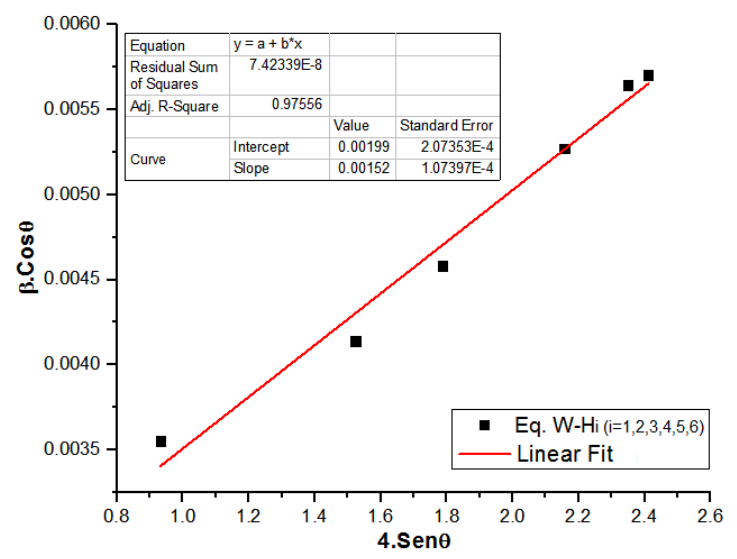

Figura 14. Ploteo Williamson-Hall de la fase $\mathrm{Cu}_{2} \mathrm{Se}$.

La ecuación de la recta resultante se expresa como:

\begin{tabular}{|c|c|c|c|c|c|c|}
\hline \multirow{16}{*}{$0.00199+$} & Fase & (hkl) & $2 \theta\left(^{\circ}\right)$ & $\beta($ rad $)$ & $B * \cos (\theta)$ & \multirow{2}{*}{$\frac{4 * \operatorname{sen}(\boldsymbol{\theta})}{0.72123}$} \\
\hline & \multirow{15}{*}{$\mathrm{Cu}_{3} \mathrm{Se}_{2}$} & 210 & 20.77532 & 0.00330 & 0.00325 & \\
\hline & & 101 & 25.0542 & 0.00327 & 0.00319 & 0.86761 \\
\hline & & 200 & 27.87298 & 0.00332 & 0.00322 & 0.96338 \\
\hline & & 111 & 28.73706 & 0.00338 & 0.00328 & 0.99263 \\
\hline & & 210 & 31.25084 & 0.00340 & 0.00328 & 1.07739 \\
\hline & & 201 & 35.04784 & 0.00360 & 0.00344 & 1.20442 \\
\hline & & 211 & 37.85352 & 0.00377 & 0.00356 & 1.29744 \\
\hline & & 220 & 39.85598 & 0.00389 & 0.00365 & 1.36336 \\
\hline & & 200 & 42.35128 & 0.00405 & 0.00378 & 1.44491 \\
\hline & & 111 & 44.8093 & 0.00415 & 0.00383 & 1.52458 \\
\hline & & 210 & 45.37992 & 0.00433 & 0.00399 & 1.54298 \\
\hline & & 201 & 47.09582 & 0.00459 & 0.00421 & 1.59806 \\
\hline & & 211 & 47.67942 & 0.00436 & 0.00398 & 1.61672 \\
\hline & & 220 & 49.89848 & 0.00462 & 0.00419 & 1.68726 \\
\hline & & 111 & 51.49134 & 0.00478 & 0.00430 & 1.73751 \\
\hline $0.00152(X)$ & & & & & (12) & \\
\hline
\end{tabular}


Relacionando los términos de las ecuaciones 11 y 12 se tiene:

$$
\begin{gathered}
\frac{K \lambda}{D}=0.00199 \\
\frac{(0.9 * 0.1546 \mathrm{~nm})}{D}=0.00199 \\
D=69.92 \mathrm{~nm} \\
\varepsilon=0.00152
\end{gathered}
$$

Para el caso de la fase Cu3Se 2 presente en 12 (b) se empleó el mismo procedimiento ajustando

\begin{tabular}{|c|c|c|c|}
\hline Función & & PsdVoig & \\
\hline \multirow{3}{*}{$\begin{array}{l}\text { Plano } \\
(111)\end{array}$} & $\begin{array}{c}\text { Parámetr } \\
0\end{array}$ & Valor & $\begin{array}{c}\text { Error } \\
\text { estándar }\end{array}$ \\
\hline & $\mathrm{Y}_{0}$ & -3.0955 & 2.41503 \\
\hline & $\begin{array}{c}\mathrm{X}_{\circ} \\
\mathrm{A} \\
\mathrm{W}\left({ }^{\circ}\right) \\
\mathrm{mu}\end{array}$ & $\begin{array}{c}26.95876 \\
658.312 \\
0.20925 \\
0.63513\end{array}$ & $\begin{array}{c}0.001 \\
7.16997 \\
0.00236 \\
0.02827\end{array}$ \\
\hline $\mathrm{Chi}^{2}$ & & $\begin{array}{l}462.47244 \\
6\end{array}$ & \\
\hline $\mathrm{R}^{2}$ & & 0.99725 & \\
\hline
\end{tabular}
los picos y registrando los valores de $2 \Theta$ y $\beta$ en la tabla 4 . Estos datos son empleados para plotear el gráfico de la figura 15 , obteniendo un $\mathrm{D}=64.79 \mathrm{~nm}$ y $\varepsilon=0.00117$.

Tabla 4. Datos de los picos de la fase $\mathrm{Cu}_{3} \mathrm{Se}_{2}$.

Convirtiendo y reemplazando los valores de Xc $\left(13.47938^{\circ}\right)$ y W $\left(0.20925^{\circ}=0.00365211 \mathrm{rad}\right)$ en la ecuación de Williamson-Hall:

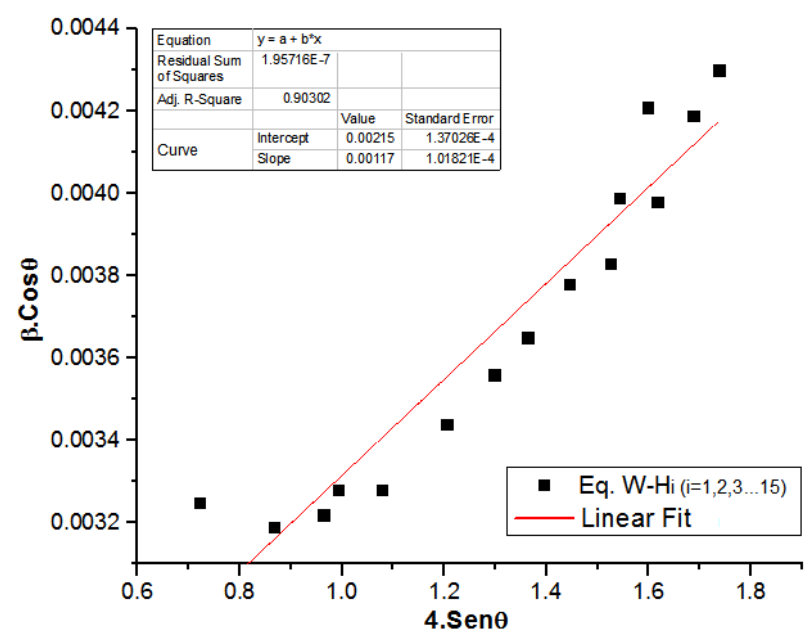

Figura 15. Ploteo Williamson-Hall de la fase $\mathrm{Cu}_{3} \mathrm{Se}_{2}$. 
El tamaño del cristalito y la tensión de la nanoestructura $\mathrm{Cu}_{2} \mathrm{Se}$ preparada por mecanosíntesis se realizó también por deconvolución, ajustando con la función PsdVoigtl al pico correspondiente al plano (220) de mayor intensidad presente en los difractogramas de las muestras molidas a 1, 3, 6 y 12 horas mostrados en la figura 7. La figura 16 muestra el ajuste del mencionado pico perteneciente a la muestra molida durante la primera hora, mientras la tabla 5 presenta los valores respectivos de los parámetros obtenidos.

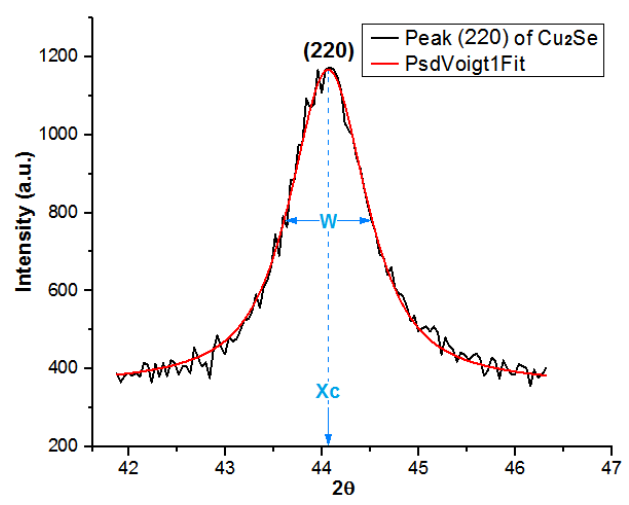

Figura 16. Ajuste del pico (220) a 1 hora de molienda.

Tabla 5. Datos del pico (220).

\begin{tabular}{lccc}
\hline Función & \multicolumn{3}{c}{ PsdVoigt1 } \\
& Parámetro & Valor & Error estándar \\
& $\mathrm{Y}_{0}$ & 356.76795 & 27.8568 \\
& $\mathrm{X}_{\mathrm{c}}$ & 44.14103 & 0.00636 \\
Plano & $\mathrm{A}$ & 596.02138 & 119.38411 \\
$(220)$ & $\mathrm{W}$ & 0.83867 & 0.01909 \\
& $\mathrm{mu}$ & -0.51872 & 0.53032 \\
\hline $\mathrm{Chi}^{2}$ & \multicolumn{3}{c}{1309.04184} \\
\hline $\mathrm{R}^{2}$ & \multicolumn{3}{c}{0.98386}
\end{tabular}

Los datos de la tabla 5 se emplearon en la ecuación de Scherrer:

$$
\begin{gathered}
D=\frac{0.9 * \lambda}{\beta * \cos \theta} \\
D=\frac{0.9 * 0.15406}{0.01463758 * \cos (22.070515)} \\
D=9.7 \mathrm{~nm}
\end{gathered}
$$


Además, la tensión en la nanoestructura se calcula mediante:

$$
\begin{gathered}
\beta=4 \varepsilon \tan \theta \\
0.01463758=4 \varepsilon \tan (22.070515) \\
\varepsilon=0.00902
\end{gathered}
$$

Por lo tanto, el diámetro promedio del cristalito calculado a la primera hora de molienda fue de $9.7 \mathrm{~nm}$ y la tensión de la nanoestructura 0.00902, el mismo método se emplea en los demás difractogramas a las 3, 6 y 12 horas registrando los datos en la tabla 6 . Una forma de observar la evolución del tamaño de cristalito y la tensión entre las partículas durante cada intervalo de tiempo es utilizar los datos de la tabla 6 para realizar el gráfico mostrado en la figura 17 donde se aprecia que al término de las 12 horas de molienda mecánica, las microtensiones de las nanoestructuras se incrementan conforme el tamaño del cristalito de la nanoestructura formada decrece hasta los $8.5 \mathrm{~nm}$.

Tabla 6. Parámetros de las muestras molidas a 1,3, 6 y 12 horas.

\begin{tabular}{ccccccl}
\hline Mecanosíntesis & $(\mathbf{h k l})$ & Tiempo (h) & $\boldsymbol{\Theta}\left({ }^{\circ}\right)$ & $\boldsymbol{\beta}(\mathbf{r a d})$ & $\boldsymbol{\varepsilon}$ & $\mathbf{D}(\mathbf{n m})$ \\
\hline \multirow{3}{*}{$\mathrm{Cu}_{2} \mathrm{Se}$} & & 1 & 22.0705 & 0.0146375 & 0.00902 & 9.7 \\
& \multirow{2}{*}{220} & 3 & 22.0361 & 0.0158980 & 0.00982 & 8.9 \\
& & 6 & 21.9995 & 0.0155771 & 0.00964 & 9.2 \\
& & 12 & 22.0336 & 0.0166859 & 0.01031 & 8.5
\end{tabular}

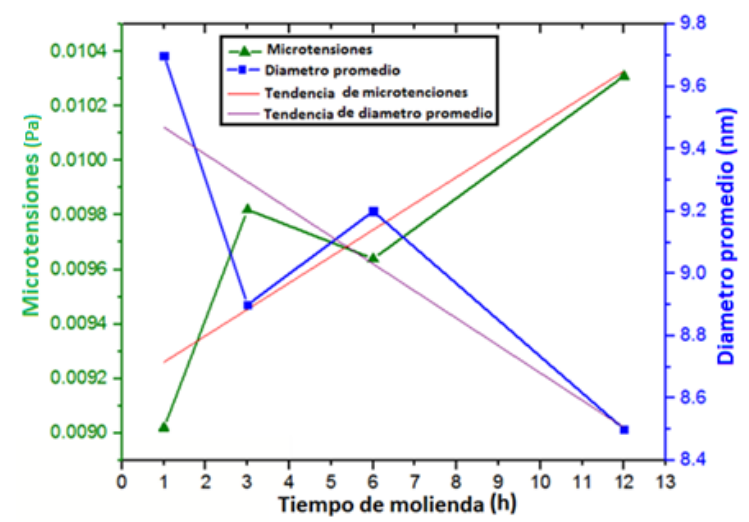

Figura 17. Evolución del tamaño del cristalito y microtensión de las muestras molidas a $1,3,6$ y 12 horas.

Estudio de la morfología y composición química de las muestras

La figura 18 pertenece a la MEB de la muestra producida por mecanosíntesis después de 12 horas de molienda. La imagen a 300X en (a) presenta una vista general de la muestra, la cual presenta fragmentos de diversos tamaños debido al continuo impacto ocurrido entre las 
villas y las partículas de polvo que son sometidas a procesos repetitivos de deformación, fractura y soldadura. Al aumentar la resolución a 1600 y $2400 X$ en (b) y (c) se observa mayor separación de las partículas por el acercamiento al tomar las imágenes, también se observa con claridad la variedad de tamaños de los fragmentos y sus defectos superficiales, los cuales son generadores de superficies químicamente muy activas. Las grietas y fracturas evidencian los efectos de la molienda mecánica de alta energía, estas imperfecciones se aprecian mejor cuando se realiza un aumento de $3000 \mathrm{X}$ en (d).
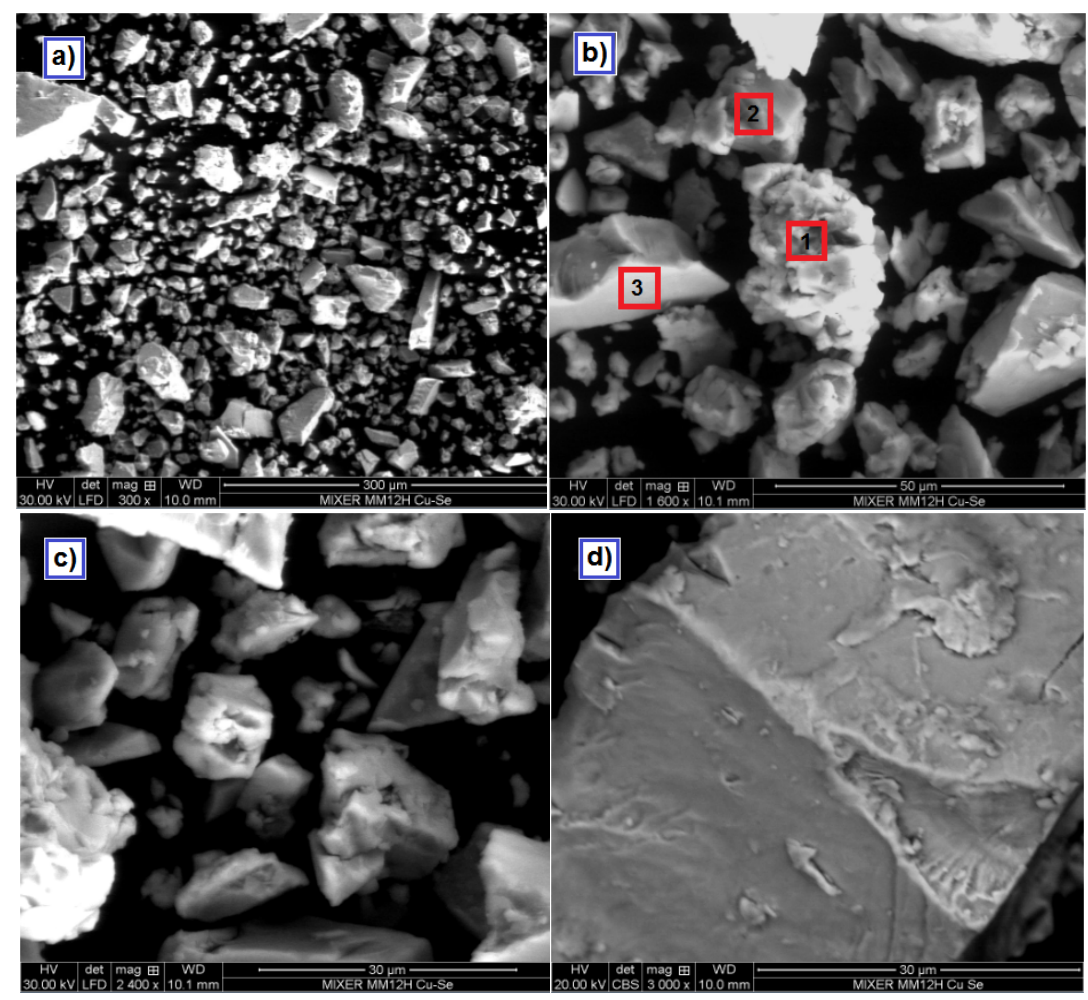

Figura 18. Imagen MEB de las nanoestructuras $\mathrm{Cu} 2 \mathrm{Se}$ producidas por mecanosíntesis a diferentes magnificaciones a) 300X; b) 1600X; c) 2400X; d) 3000X.

La composición elemental de la muestra se realizó mediante el análisis EDS (Energy Dispersive Spectroscopy) en la zona 1 de la figura 18 (b) y se observa en la figura 19, la tabla 7 muestra la composición química puntual. Los porcentajes atómicos mantienen aproximadamente la relación $2: 1$, valor que concuerda con la proporción $\mathrm{Cu}: \mathrm{Se}=2: 1$ utilizada durante todo el proceso de molienda. 


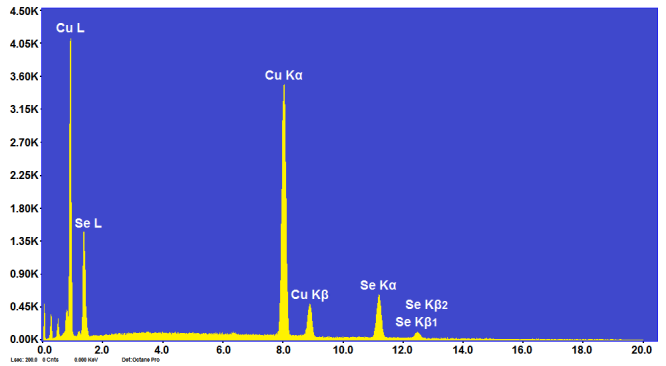

Figura 19. Difractograma EDS de la zona 1 del MEB $\mathrm{Cu}_{2} \mathrm{Se}$.

Tabla 7. Datos espectrales del EDS de la muestra $\mathrm{Cu}_{2} \mathrm{Se}$.

\begin{tabular}{cccccc}
\hline Elemento & Peso\% & Atómico\% & Error\% & K & $\mathbf{Z}$ \\
\hline $\mathrm{Cu} \mathrm{K}$ & 62.04 & 67.00 & 0.43 & 0.6647 & 1.0274 \\
$\mathrm{Se} \mathrm{K}$ & 37.96 & 33.00 & 1.45 & 0.3376 & 0.9529
\end{tabular}

Las imágenes MEB que se observan en la figura 20 pertenecen a la muestra $\mathrm{CuSe}$ (B) sintetizada mediante la técnica microondas. La imagen con un aumento de $300 \mathrm{X}$ en (a) muestra en la superficie la formación de aglomerados de diferentes tamaños señalados en las zonas 1, 2, 3 y 4. Ellos son originados por la interacción de las nanopartículas que se forman durante la etapa de crecimiento debido a la gran energía superficial y proximidad que presentan. La siguiente imagen (b) aumentada $2400 \mathrm{X}$ de la partícula señalada en la zona 3, muestra cómo las pequeñas formaciones esféricas se fueron aglomerando alrededor a ella.

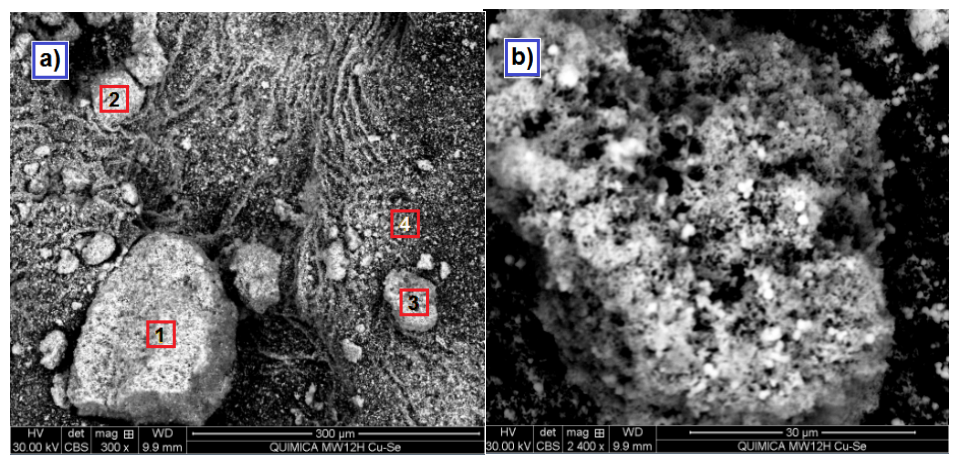

Figura 20. Imagen MEB de la muestra CuSe (B) a dos aumentos a) 300X; b) $2400 X$. 
Un aumento de $2400 \mathrm{X}$ sobre la zona 4 de la figura 20 (a) se aprecia en la figura 21, donde se aprecia mejor cómo las partículas se encuentran dispersas en la superficie y siguen la tendencia de aglomerarse, este efecto impide que en la superficie predominen partículas de formas esféricas como las señaladas en la misma figura con zonas circulares de color rojo. Las imágenes mostradas con sus respectivas resoluciones son las máximas que se pudieron alcanzar empleando el microscopio electrónico de barrido FEI Quanta - 650, la única forma de encontrar algunas posibles imperfecciones y defectos superficiales es empleando la microscopía electrónica de transmisión (TEM) lo cual no se hace en el país, esta es una herramienta mucho más poderosa capaz de analizar a alta resolución a nivel nano, para medir el tamaño de nano partículas, medición del tamaño de grano, tamaño de cristalito, disposición atómica en el material.

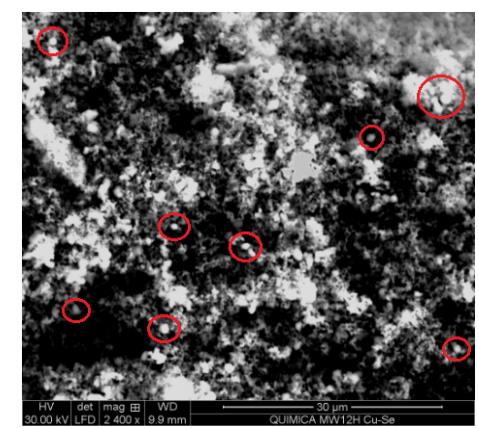

Figura 21. Imagen MEB de la muestra CuSe (B) sobre la zona 4 a $2400 \mathrm{X}$.

\section{Estudio de la energía de banda prohibida}

La energía de banda prohibida directa del seleniuro de cobre se determinó indirectamente empleando el análisis UV-Vis en la muestra CuSe (C), sintetizada mediante la técnica de microondas donde se obtuvo solamente la fase $\mathrm{Cu} 1.8 \mathrm{Se}$. Se preparó una serie de dispersiones a diferentes concentraciones, luego de realizar las lecturas a todas las muestras estas presentaron una banda de absorción característica entre 450 y $550 \mathrm{~nm}$ como se observa en la figura 22.

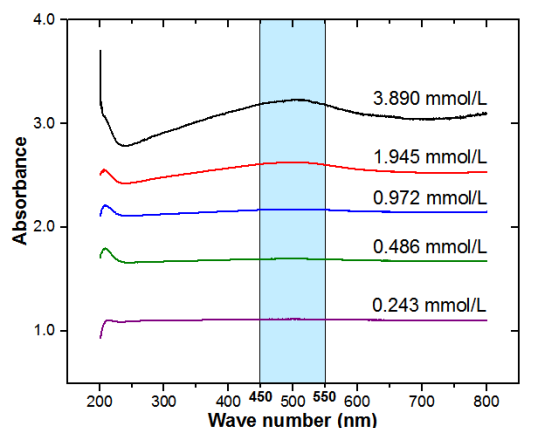

Figura 22. Imagen MEB de la muestra CuSe (B) sobre la zona 4 a 2400X. 
Cuando se realizó la medida de la absorbancia a la dispersión cuya concentración fue de $0.243 \mathrm{mmol} / \mathrm{L}$, apareció una banda característica de absorción con una señal más débil del semiconductor aproximadamente a $260 \mathrm{~nm}$, la cual se visualiza al graficar el espectro de absorción que se muestra en la figura 23.

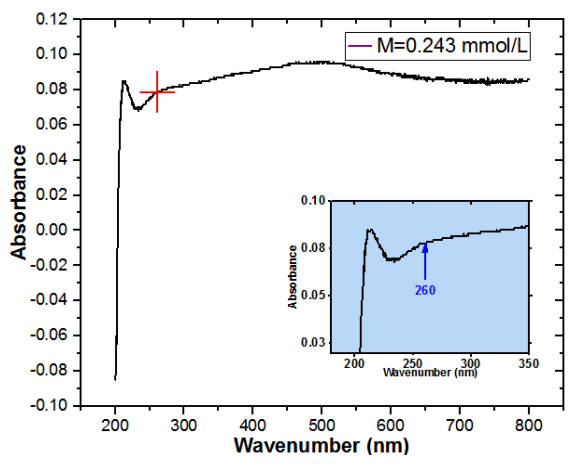

Figura 23. Espectro UV-Vis de la dispersión a $0.243 \mathrm{~mol} / \mathrm{L}$.

Los valores de las absorbancias obtenidas con sus respectivas longitudes de ondas del espectro UV-vis presentes en la figura 23, se trasladan a hojas de cálculo y se emplean para realizar el ploteo de Tauc, graficando $(\mathrm{A} 0 * \mathrm{E})^{2}$ vs $(\mathrm{Eg})$ tal como se presenta en la figura 24. Además, en la misma figura se traza una línea recta que pasa por la mayor cantidad de puntos de la gráfica, con la finalidad de ajustar los datos experimentales a la recta que intercepta a la abscisa por lo tanto "Y" se hace cero y "X" proporciona el valor aproximado de Eg de $1.5 \mathrm{eV}$.

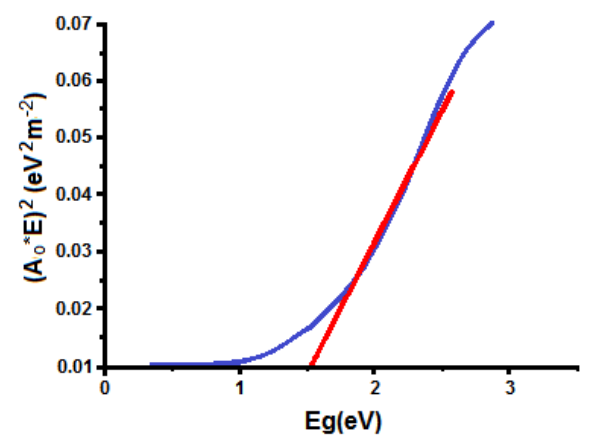

Figura 24. Ploteo de Tauc de la muestra $\mathrm{CuSe}(\mathrm{C})$.

De la misma forma, se realiza el análisis espectrofotométrico a la nanoestructura $\mathrm{Cu} 2 \mathrm{Se}$ sintetizada mediante mecanosíntesis, la figura 25 presenta su espectro de absorción UV-VIS a una concentración de $0.253 \mathrm{mmol} / \mathrm{L}$, donde se observa una banda de absorción máxima aproximadamente a $340 \mathrm{~nm}$. Las absorciones son usadas para el ploteo de Tauc, graficando 
(A0*E) 2 vs (Eg) como en el caso anterior, donde la energía de banda prohibida directa se obtiene al trazar una tangente sobre la curva cuyo intercepto con el eje de las abscisas arroja como resultado un valor aproximado $\mathrm{Eg}$ de $1.75 \mathrm{eV}$ (figura 26).

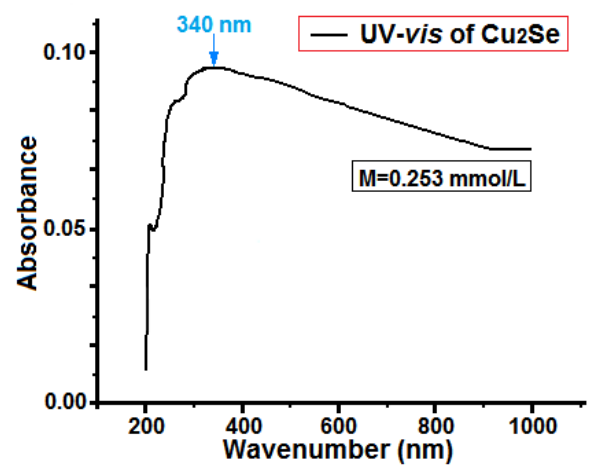

Figura 25. Espectro UV-Vis de la muestra $\mathrm{Cu}_{2} \mathrm{Se}$ sintetizada por mecanosíntesis.

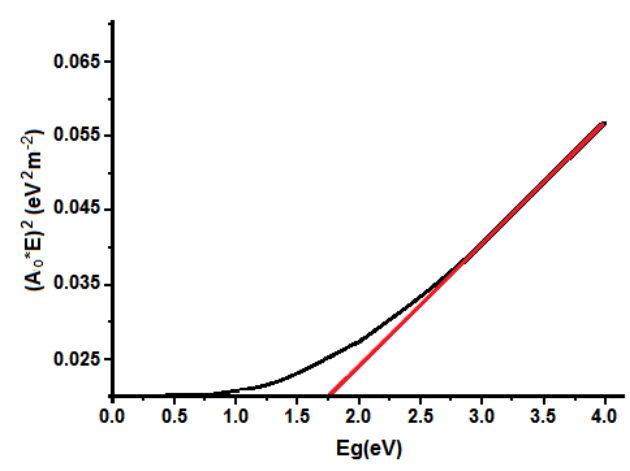

Figura 26. Ploteo de Tauc de la muestra $\mathrm{Cu}_{2} \mathrm{Se}$.

\section{Determinación cualitativa de metales presentes en las muestras}

El análisis de las muestras para detectar elementos en bajas concentraciones se realizó mediante la fluorescencia de rayos X. El espectro FR-X de la muestra de seleniuro de cobre producido por mecanosíntesis se observa en la figura 27, notando la presencia de cuatro picos preponderantes correspondientes a los elementos cobre y selenio. 


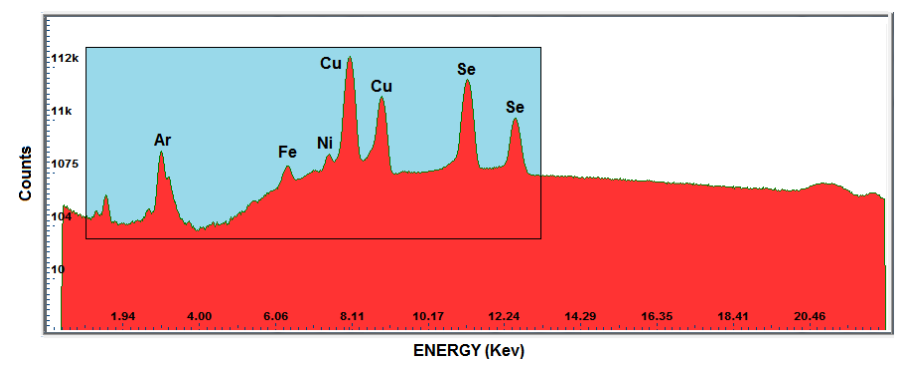

Figura 27. Espectro FR-X de la muestra Cu2Se.

En la figura 28 se presenta una vista parcial del espectro FR-X, donde la región energética aproximada de análisis fue de 6 a $13 \mathrm{KeV}$, es la zona de mayor importancia para el presente estudio, pues aquí se encuentran las energías de emisión de los elementos más abundantes, como el cobre, cuyas bandas espectrales se encuentran en las zonas de energías correspondientes a la capa Ka acopladas (KL2 $=8.028$ y KL3 $=8,048 \mathrm{KeV}$ ) y la capa Kb $(\mathrm{KM} 2=8,905 \mathrm{KeV})$. El segundo elemento en mayor proporción corresponde al selenio con la capa Ka $(\mathrm{KL} 2=11.182$ y KL3 $=11.222 \mathrm{KeV})$ y la capa Kb $(\mathrm{KM} 3=12.494$ y KN3 = $12.652 \mathrm{KeV}$ ). También se aprecia la presencia de Argón en buena proporción en respuesta a la radiación asociada al material entre la muestra y el equipo (aire); además, la presencia de trazas de aluminio, hierro, níquel, zinc, cloro y azufre en muy baja proporción respecto a los metales presentes debido al contacto de los reactivos con los materiales utilizados en el proceso de molienda mecánica.

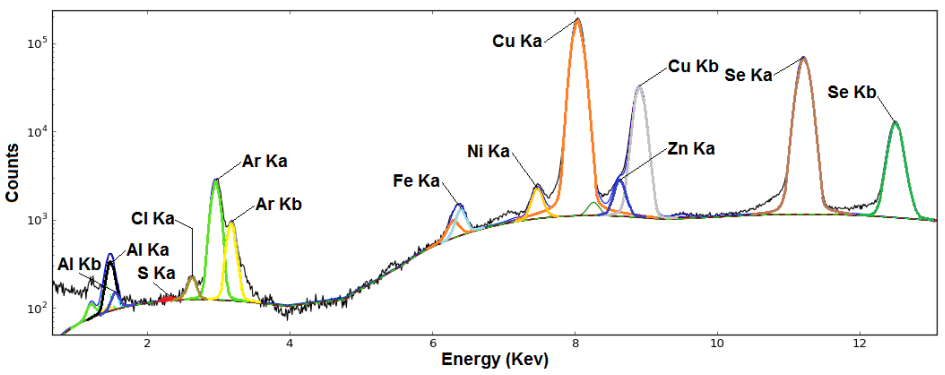

Figura 28. Espectro FRX completo del $\mathrm{Cu}_{2} \mathrm{Se}$ utilizando el programa PyMca.

Las siguientes muestras analizadas de seleniuro de cobre corresponden a las sintetizadas por la vía microondas, el espectro FR-X de la muestra $\mathrm{CuSe}(\mathrm{A})$ se muestra en la figura 29, donde se indican los principales elementos identificados como el cobre, selenio y azufre. La presencia de este último elemento se debe al compuesto $\mathrm{Na}_{2} \mathrm{SO}_{3}$ que es el agente reductor utilizado en todas las síntesis vía microondas. 


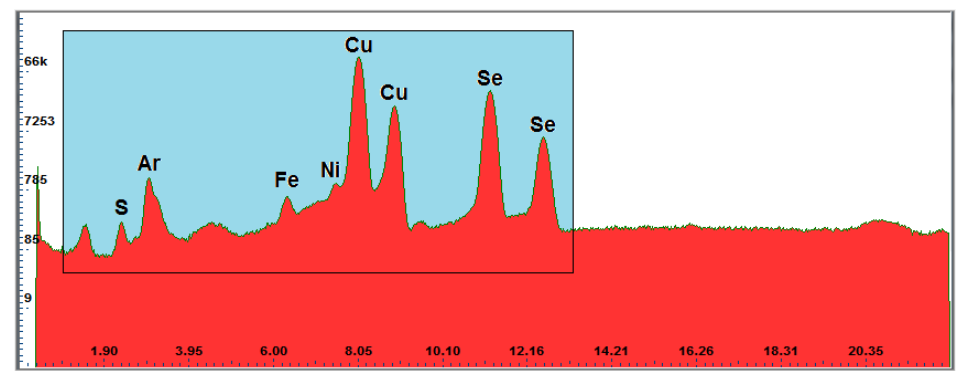

Figura 29. Espectro FRX de la muestra $\mathrm{CuSe}(\mathrm{A})$.

\section{CONCLUSIONES}

Se sintetizaron nanoestructuras de seleniuro de cobre mediante las técnicas microondas y mecanosíntesis. En la muestra $\mathrm{CuSe}(\mathrm{A})$ con una proporción $\mathrm{Cu}: \mathrm{Se}=2: 1$, se formaron las fases $\mathrm{Cu}_{3} \mathrm{Se}_{2}+\mathrm{Cu}_{2} \mathrm{Se}$, en el $\mathrm{CuSe}(\mathrm{B})$ con una proporción $\mathrm{Cu}: \mathrm{Se}=2: 1$ se genera la mezcla de fases $\mathrm{Cu}_{3} \mathrm{Se}_{2}+\mathrm{Cu}_{1.8} \mathrm{Se}$ y solo aparece una única fase de $\mathrm{Cu}_{1.8} \mathrm{Se}$ en $\mathrm{CuSe}(\mathrm{C})$ al emplear la proporción $\mathrm{Cu}: \mathrm{Se}=3: 2$. Por lo tanto, la proporción $\mathrm{Cu}: \mathrm{Se}$ empleada en los tres experimentos tiene un efecto significativo en la formación de las fases de seleniuro de cobre. La técnica microondas permitió obtener nanoestructuras solamente con fases de seleniuro de cobre sin impurezas, lo cual hace que sea la técnica más adecuada para la fabricación de celdas solares, no se recomendaría emplear la mecanosíntesis para producir seleniuro de cobre ya que se obtuvo una fase ajena impura de óxido de cobre y trazas de metales que solo se pudieron detectar mediante el análisis FR-X. La morfología superficial de las estructuras de seleniuro de cobre, dependen del método empleado para sintetizarlas, el incremento de las imperfecciones y defectos superficiales del $\mathrm{Cu}_{2}$ Se producido por la molienda de alta energía facilitaría el dopaje para la producción de materiales más complejos y con otros usos. La banda de energía prohibida directa obtenida de las muestras producidas por ambas técnicas de síntesis se encuentra entre 1 y $2 \mathrm{eV}$, por lo tanto, estos materiales pueden ser utilizados para fabricar células solares ${ }^{24}$.

\section{AGRADECIMIENTO}

Al Programa Nacional de Innovación para la Competitividad y Productividad (Innóvate Perú) del Ministerio de la Producción que a través del financiamiento al proyecto No 357-PNICPPIBA-2014, denominado "Estudio y desarrollo de compósitos termoplásticos bactericidas para el sector de envases plásticos de uso comercial (PET - Poliethylene Glycol Terephthalate) conteniendo nanocobre y nanoplata. (Masterbatch de PET con nanocobre y nanoplata)". 


\section{REFERENCIAS BIBLIOGRÁFICAS}

1. Bhuse VM, Hankare PP. A simple, convenient, low temperature route to grow polycrystalline copper selenide thin films. Mater Chem Phys. 2003: 80: 82-88.

2. Subas R, Jagminas A. Optical investigation and application of copper selenide nanowires. Lith J Phys. 2007; 47: 361-364.

3. Yeong-Hui S, Byung-Seok L. Facile Microwave-Assisted Synthesis of Multiphase CuInSe2 Nanoparticles and Role of Secondary CuSe Phase on Photovoltaic Device Performance. J Phys Chem C. 2013; 117: 9529-9536.

4. Chenglong S, Xuekui X. Atomic-Level Characterization of Dynamics of Copper Ions in CuAgSe. J Phys Chem C. 2016; 120: 3229-3234.

5. Jun X, Weixin Z, Zeheng Y. Large-Scale Synthesis of Long Crystalline Cu2-xSe Nanowire Bundles by Water-Evaporation-Induced -Self-Assembly and Their Application in Gas Sensing. Adv Funct Mater. 2009; 19: 1759-1766.

6. Lakshmikumar ST, Rastogi AC. Selenization of $\mathrm{Cu}$ and In thin films for the preparation of selenide photo-absorber layers in solar cells using Se vapour source. Sol. Energy Mater Sol Cells. 1994; 32: 7-19.

7. Kaviyarasu K, Ayeshamariam A. Solution processing of CuSe quantum dots: Photocatalytic activity under RhB for UV and visible-light solar irradiation. Mater Sci Eng B. 2016; 210: 1-9.

8. Kingston SJ, Haswell SJ. Microwave-enhanced Chemistry. J Am Chem Soc. 1997; 1: 3-20.

9. Peña VA. Mecanosíntesis. Revista de investigación de Física. 1998; 1: 1-25.

10. Xie $Y$, Zheng X. Sonochemical synthesis and mechanistic study of copper selenides Cu2-xSe, $\beta$-CuSe, and Cu3Se2. Inorg Chem. 2002; 41: 387-392.

11. Dhasade S, Thombare J. Copper selenide nanorods grown at room temperature by electrodeposition. Mater Sci Semicond Process. 2015; 30: 48-55.

12. Peranantham $\mathrm{P}$, Jeyachandran YL. The effect of annealing on vacuum-evaporated copper selenide and indium telluride thin films. Mater Charact. 2007; 58: 756-764.

13. Gurin VS, Alexeenko A. Copper and copper selenide nanoparticles in the sol-gel matrices: Structural and optical. Mater Sci Eng C. 2006; 26: 952-955.

14. Lakshmi M, Bindu K. Chemical bath deposition of different phases of copper selenide thin films by controlling bath parameters. Thin Solid Films. 2000; 370: 89-95.

15. Naghavi N, Spiering S. High-efficiency copper indium gallium diselenide (CIGS) solar cells with indium sulfide buffer layers deposited by atomic layer chemical vapor deposition (ALCVD). Photovoltaics. 2003; 11: 437-443.

16. Ming X, Yong Z. Fabrication and Electrochemical Characterization of Copper Selenide Thin Films by Pulsed Laser Deposition. J Electrochem Soc. 2006; 153: 2262-2268.

17. Kumar P, Singh K. Template free-solvothermaly synthesized copper selenide (CuSe, $\mathrm{Cu} 2-\mathrm{xSe}, \beta-\mathrm{Cu} 2 \mathrm{Se}$ and $\mathrm{Cu} 2 \mathrm{Se}$ ) hexagonal nanoplates from different precursors at low temperature. J Cryst Growth. 2010; 312: 2804-2813.

18. Frangis N, Manolikas C. Vacancy-Ordered Superstructures in Cu2Se. Phys Status Solidi. 1991; 126: 9-22.

19. Kalenga MP, Govindraju S. Fabrication of a Schottky Device Using CuSe Nanoparticles: 
Colloidal versus Microwave Digestive Synthesis. J Nanosci Nanotechnol. 2015; 15 : 4480-4486.

20. Yong-Qiang L, Feng-Xia W. Facile Microw ave-Assisted Synthesis of Klockmannite CuSe Nanosheets and Their Exceptional Electrical Properties. Sci Rep. 2014; 4: 1-8.

21. Machado KD, de Lima JC, Grandi TA, Campos CE, Maurmann CE, Gasperini AA, et al. Structural study of $\mathrm{Cu}(2-\mathrm{x}) \mathrm{Se}$ alloys produced by mechanical alloying. Acta Crystallogr B. 2004; 60:282-6.

22. Viezbicke B. Evaluation of the Tauc method for optical absorption edge determination: $\mathrm{ZnO}$ thin films as a model system. Phys Status Solidi. 2015; 1: 1-11.

23. Suryanarayana C. Mechanical Alloying and Milling. New York: Marcel Dekker; 2003. 66-68 p.

24. Bottecchia OL. A Model of the Growth of Copper Selenide Thin Films Controlled by Diffusion and Chemical Reaction. J Braz Chem. 1998; 9: 515-520. 